\title{
O uso da dexametasona como indutor de parto em vacas Nelore submetidas a condições de estresse: implicações fetais - relato de caso
}

Fábio de Carvalho Lahr ${ }^{[a]}$, Renan Braga Paiano[a], Eduardo Harry Birgel Junior ${ }^{[a]}$, Daniela Becker Birgel[ ${ }^{[a]}$, Amanda Almeida Santos $\left[{ }^{[b]}\right.$

\footnotetext{
[a] Faculdade de Zootecnia e Engenharia de Alimentos, Universidade de São Paulo (USP), Pirassununga, SP, Brasil

${ }^{[b]}$ Faculdades Unidas do Vale do Araguaia (UNIVAR), Barra do Garças, MT, Brasil
}

*Autor correspondente

e-mail: fabio.de.lahr@gmail.com

\section{Resumo}

O mecônio liberado durante processos de parturição é uma condição confirmatória do estresse fetal, sendo esta condição caracterizada pelo tingimento de amarelo-amarronzado dos pêlos e mucosas do recémnascido. Quando o mecônio é aspirado pelo bezerro, ocorrerão alterações de permeabilidade da parede alveolar devido à redução da estabilidade da monocamada formada pelo líquido surfactante em razão dos fosfolipídeos oriundos do mecônio. Como consequência, o bezerro apresentará áreas pulmonares atelectásicas, condição que repercute diretamente sobre a função cardíaca. 0 presente trabalho relata um caso no qual um lote de nove vacas Nelore, com gestações a termo, foram submetidas à mudança de piquete, alterando-se o lote de uma condição de pastejo extensivo para uma condição de confinamento em um piquete de $625 \mathrm{~m}^{2}$ com alimentação ad libitum. Os animais foram observados diariamente e submetidos a manejos de coleta de sangue e urina. 0 grupo A, de quatro vacas, foi selecionado aleatoriamente para a indução do parto com $20 \mathrm{mg}$ de dexametasona administrado na veia jugular 24 horas antes da casariana, procedimento que ocorreu 10 dias após a chegada dos animais. 0 grupo B, de cinco vacas, foi selecionado aleatoriamente para que estas não fossem induzidas antes da cesariana, procedimento que ocorreu 18 dias após a chegada dos animais. Paro o grupo A, no período compreendido entre a chegada e o parto, houve redução de peso de 617,75 Kg para 535,5 Kg; aumento da concentração de corpos cetônicos urinários mensurados na tira de urinálise de $0 \mathrm{mg} / \mathrm{dL}$ para $20,0 \mathrm{mg} / \mathrm{dL}$; redução do pH urinário mensurado em potenciômetro laboratorial de 7,64 para 5,736; aumento do BHB sanguíneo mensurado no aparelho Abbot Xceed de 1,125 para 2,93 mmol/L. Paro o grupo B, no período compreendido entre a chegada e o parto, houve redução de peso de 656,4 Kg para 580,5 Kg; aumento da concentração de corpos cetônicos urinários mensurados 
na tira de urinálise de $0 \mathrm{mg} / \mathrm{dL}$ para 5,0 mg/dL(com pico de $28 \mathrm{mg} / \mathrm{dL}$ no dia 8); redução do pH urinário mensurado em potenciômetro laboratorial de 7,33 para 5,88; aumento do BHB sanguíneo mensurado no aparelho Abbot Xceed de 0,76 para 1,571 mmol/L. 0 grupo A apresentou um animal com prenhez gemelar, perfazendo um total de cinco bezerros. Dos cinco bezerros, um (20\%) apresentou tingimento por mecônio e nenhum (0\%) morreu até 48 horas de vida. 0 grupo B também apresentou um animal com prenhez gemelar, perfazendo um total de seis bezerros. Dos seis bezerros, três (50\%) apresentaram tingimento por mecônio e quatro $(66,6 \%)$ morreram até 48 horas de vida. Para as condições de estresse e redução de consumo ocorridas neste lote, o uso da dexametasona reduziu a porcentagem de fetos nascidos tingidos por mecônio e a mortalidade até 48 horas. 